Article

\title{
Effect of Additions of Ceramic Nanoparticles and Gas-Dynamic Treatment on Al Casting Alloys
}

\section{Konstantin Borodianskiy $^{1}{ }^{*}$, Vadim Selivorstov ${ }^{2}$, Yuri Dotsenko ${ }^{2}$ and Michael Zinigrad ${ }^{1}$}

1 Department of Chemical Engineering and Materials, Ariel University, Ariel 40700, Israel; E-Mail: mzinigrad@ ariel.ac.il

2 Electrometallurgical Faculty, The National Metallurgical Academy of Ukraine, 4 Gagarina Ave., Dnepropetrovsk 49600, Ukraine; E-Mails: s-v-y@mail.ru (V.S.); yuri.dotsenko@mail.ru (Y.D.)

* Author to whom correspondence should be addressed; E-Mail: konstantinb@ariel.ac.il; Tel.: +972-3-9066-217; Fax: +972-3-9066-234.

Academic Editor: Hugo F. Lopez

Received: 18 October 2015 / Accepted: 27 November 2015 / Published: 3 December 2015

\begin{abstract}
In recent years, improving the mechanical properties of metals has become the main challenge in the modern materials and metallurgical industry. An alloying process is usually used to achieve advanced performance of metals. This paper, however, describes an alternative approach. Modification with ceramic nanoparticles, gas-dynamic treatment (GDT) and a combined treatment were investigated on a hypoeutectic Al-Si A356 alloy. Microstructural studies revealed the refinement of coarse $\alpha$-Al grains and the formation of distributed eutectic Si particles. Subsequent testing of the mechanical properties revealed improvement after applying each of the treatments. The best results were obtained after modification with TiCN nanoparticles followed by GDT; the tensile strength and elongation of the A356 alloys increased by $18 \%$ and $19 \%$, respectively.
\end{abstract}

Keywords: aluminum casting; nanomaterials; casting; gas-dynamic treatment; mechanical properties 


\section{Introduction}

In the last two decades, the materials industry has become more interested in the production of $\mathrm{Al}$ alloys due to their advanced properties, such as high thermal and electrical conductivity and relatively low density, 1/3 of steel [1]. Unfortunately, Al alloys show relatively low mechanical properties compared to those of steel. Traditionally, strengthening of $\mathrm{Al}$ is achieved by well-known alloying processes, involving the addition of certain elements to affect the final properties of the metals. This technology has become increasingly less efficient due to the large amount of expensive materials used to obtain the desirable technological characteristics.

Aluminum casting alloy A356 is widely used in the automotive and aerospace industries, as it preserves relatively high strength at elevated temperatures. Therefore, improvement of this alloys' mechanical properties has been extensively investigated. A356 alloys' strength is conventionally improved by the alloying technique [2-7] using master alloys, by heat treatment or by applying ultrasound, which affects the crystallization process of the solidifying alloy [8-10]. Some studies have shown that the addition of $\mathrm{TiB}_{2}$ particles causes grain refinement of the alloy $[11,12]$. Other studies have demonstrated A356 modification though rear-earth metals, such as Er, La and Ce [13,14].

Modification processes can be performed with different modifiers. According to Rebinder, two types of modification processes can be distinguished [15]:

a. Inoculation: modification by refractory particles, which must have a higher melting point than the molten metal. The modification of $\mathrm{Al}$ alloy can be achieved using the following metals and compounds: $\mathrm{Ti}, \mathrm{Zr}, \mathrm{V}, \mathrm{TiC}, \mathrm{TiB}_{2}$, etc.

b. Limitation: modification by surface-active elements, which must have a relatively high solubility limit in the modified phase. The modification of Al alloy can be achieved using the following elements: B, Sr, Sb, Ba, etc.

An effective method for improving the mechanical properties of Al alloys employs solidification under severely non-equilibrium conditions, as was illustrated in [16]. Here, pressure was applied during the solidification process, and it was found that the higher the applied pressure, the more elevated the crystallization rate. Guan et al. showed improvement of Al-Si A356 alloy by applying squeeze casting, which is a type of molten metal solidification under pressure [17]. Selivorstov et al. noted the same behavior applying to Al-Si hypereutectic alloy [18].

Similarly, improvement of the mechanical properties of metals can be achieved using a method involving nano-sized particles into the melt. It is expected that nano-sized particles formed in the metal would cause some change in mechanical properties, but that its influence would be "milder" and more balanced. Several published studies indicate that the mechanical properties of Al alloy A356 can be improved by additions of $\mathrm{Al}_{2} \mathrm{O}_{3}, \mathrm{TiB}_{2}$ or TiC nanoparticles during the casting process [19-21].

The aim of the present work is to develop a combined technology using modification with nano-sized particles and gas-dynamic treatment (GDT) during the solidification of an Al-Si A356 alloy in a casting mold and to analyze its effectiveness. 


\section{Experimental Section}

Al-Si alloy A356 (Rheinfelden Alloys GmbH, Rheinfelden, Germany) was used as the bulk material. The composition of the alloy is given in Table 1 .

First, to examine the effect of GDT, a $1.2 \mathrm{~kg}$ portion of ingots of alloy A356 was melted in a Carbolyte ELF 11/14B (Hope, UK) laboratory furnace and superheated to $720{ }^{\circ} \mathrm{C}$. This was followed by the addition of $\mathrm{NaCl}, \mathrm{KCl}$ and a NITRAL C 19 (Foseco)-containing powder to prevent the alloy from oxidizing. The melt was poured into a special GDT system (Figure 1); during its solidification, inert gas argon was fed from the initial pressure of 0.1-0.2 MPa up to 1.3-1.4 MPa, until the alloy was solidified completely. Finally, the obtained casts were aged according to the $T 6$ heat treatment procedure; first, the solid solution was heat-treated at $538^{\circ} \mathrm{C}$ for $8 \mathrm{~h}$, then it was water-quenched followed by an artificially aging at $160{ }^{\circ} \mathrm{C}$ for $4 \mathrm{~h}$.

Table 1. Chemical composition of Al-Si A356.

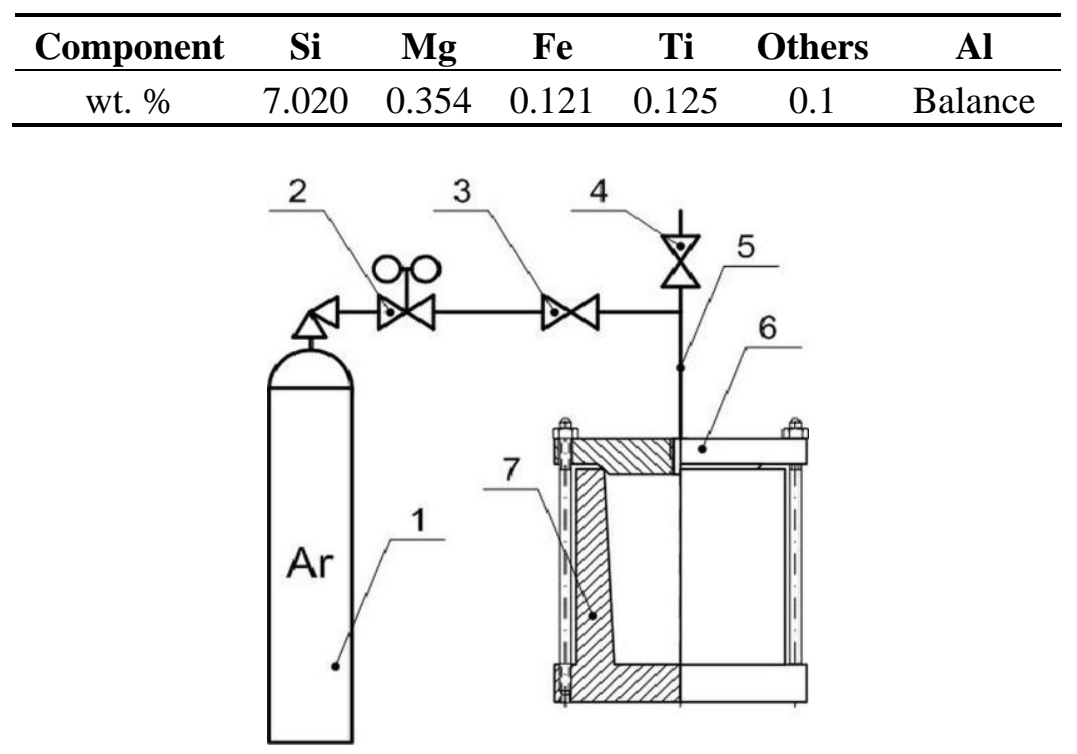

Figure 1. Gas-dynamic treatment (GDT) system used in the research. 1, inert gas (Ar) cylinder; 2, valve; 3, 4, non-return valve; 5, gas pipe; 6, solidifying container cover; 7 , solidifying container.

Next, industrial experiments were performed. A $200 \mathrm{~kg}$ portion of Al-Si alloy A356 ingots was melted in an industrial electric resistance furnace, superheated to $680{ }^{\circ} \mathrm{C}$ and subjected to the addition of DEGASAL T200 (Schaefer Chemiche Fabrik, Hennef (Sieg), Germany). Then, a modifier containing 0.01 wt. \% titanium carbonitride (TiCN) nanoparticles (Neomat Co., Riga, Latvia; N, 9.7 wt. \%; C, 9.5 wt. \%; crystallite size, $\sim 50 \mathrm{~nm}$ ) was added to the molten metal, and the mixture was kept at $680{ }^{\circ} \mathrm{C}$ for $40-60 \mathrm{~s}$. The melt was poured and aged for a given period of time, after which inert Ar gas was fed until the metal fully solidified.

To examine the shrinkage, one treated (after the addition of nanoparticles and the GDT process) specimen and one untreated specimen were poured into preheated cylindrical cast iron molds. 


\section{Characterization Techniques}

Microstructure studies were carried out using a Zeiss Axiolab optical microscope by Zeiss GmbH, Jena, Germany. Specimens of the A356 casting alloy were analyzed using Keller-Wilcox's reagent ( $3 \mathrm{~mL} \mathrm{HCl}, 5 \mathrm{~mL} \mathrm{HNO}_{3}, 1 \mathrm{~mL} \mathrm{HF}$ and $190 \mathrm{~mL} \mathrm{H}_{2} \mathrm{O}$ ) to investigate their microstructures.

The mechanical properties were measured by a P100 testing machine (Ukon Tans Ltd., Lubny, Ukraine) according to ASTM B 108-01. The modified alloys produced were compared to unmodified alloys cast under the same conditions. Hardness tests were conducted on Al alloys by a TS-B-C2 static hardness tester (NOVOTEST Ltd., Novomoskovs'k, Ukraine) before and after treatment.

The phases were identified by X-ray diffraction (XRD) analysis using a PANalytical X'Pert Pro $\mathrm{X}$-ray powder diffractometer (Almelo, The Netherlands) at $40 \mathrm{kV}$ and $40 \mathrm{~mA}$. The XRD patterns were recorded in the $2 \Theta$ range from $20^{\circ}-100^{\circ}$ (the step size was $0.03^{\circ}$, and the time per step was $3 \mathrm{~s}$ ).

The aluminum strengthening mechanism was determined from measurements taken on a JEOL JEM 2010 high-resolution transmission electron microscope (HR-TEM, Tokyo, Japan). Specially-prepared disks with a diameter of $3 \mathrm{~mm}$ were punched out of thinned $\mathrm{Al}$ and were subsequently jet-polished using a solution of $30 \%$ nitric acid and $70 \%$ methanol at $-20{ }^{\circ} \mathrm{C}$ and $10 \mathrm{~V}$.

\section{Results and Discussion}

The effect of GDT on the crystallization of A356 alloys is not limited only to refinement of the structural components. It also promotes an increase in the mutual solubility of the alloy components and, as a result, alters the eutectic concentration of the alloys.

Figure 2 shows the Al-Si phase diagram, which was obtained after GDT was applied (dashed lines). Mutual solubility of the alloys increases as the result of the diffusion rate decrease during the liquid-solid phase transformation. The diagram was constructed using the Schröder equation [22]:

$$
\begin{gathered}
\ln X=\frac{Q_{A}}{2}\left(\frac{1}{T_{A}}-\frac{1}{T}\right) \\
\ln (1-X)=\frac{Q_{B}}{2}\left(\frac{1}{T_{B}}-\frac{1}{T}\right)
\end{gathered}
$$

where $X$ is the molar concentration of component $\mathrm{A},(1-X)$ is the molar concentration of component $\mathrm{B}$, $Q_{A}$ is the latent heat of fusion of component $\mathrm{A}, Q_{B}$ is the latent heat of fusion of component $\mathrm{B}, T_{A}$ is the melting point of component $\mathrm{A}, T_{B}$ is the melting point of component $\mathrm{B}$ and $T$ is the current melting point.

In the calculations, it was assumed that the melting point of $\mathrm{Al}$ increases by $6.3 \times 10^{-3}{ }^{\circ} \mathrm{C}$ per pressure of $1 \mathrm{~atm}$ and that the melting point of Si decreases by $5.8 \times 10^{-3}{ }^{\circ} \mathrm{C}$ per pressure of $1 \mathrm{~atm}[23]$. The resultant Al-Si phase diagram is shown in Figure 2. 


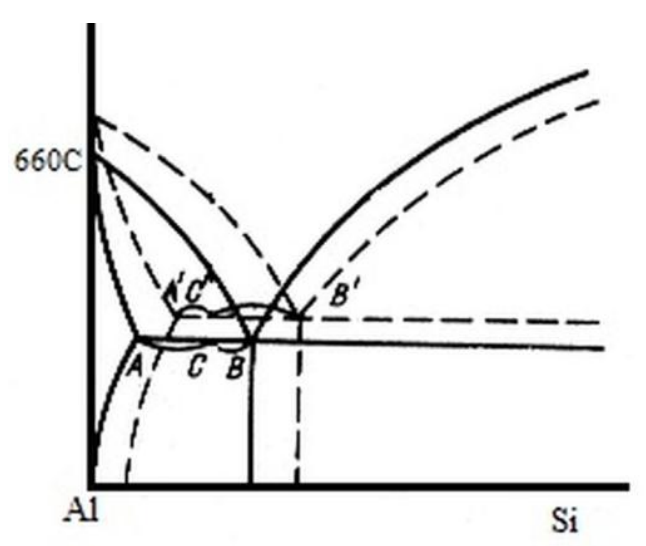

Figure 2. Al-Si phase diagram. The solid lines comprise the equilibrium phase diagram [24]. The dashed lines were added to the diagram after GDT application. This is a new image obtained by authors; new dashed lines build on a known phase diagram.

The calculations performed showed that the displacement of the eutectic point toward pure Si on the Al-Si diagram amounts to $0.003 \%$ per atmosphere.

Figure 3 shows the microstructure of A356 alloy before and after GDT. It is clearly shown that the GDT process refines the disoriented, elongated $\alpha$-Al grains into fine equiaxed grains with homogeneously-distributed eutectic Si particles. The breaking of the silicon network allows a decrease in the stress-concentration factor. Moreover, formed new Si particles prevent dislocation movement; therefore, the material shows greater strength properties.

It is also seen that A356 alloy treatment significantly refined the coarse, large, elongated $\alpha$-Al grains into fine equiaxed grains with homogeneously-distributed eutectic Si particles. Additionally, a lamellar Si structure formed in the modified alloy, similar to the modification of Al alloys by $\mathrm{Sr}$ [25].
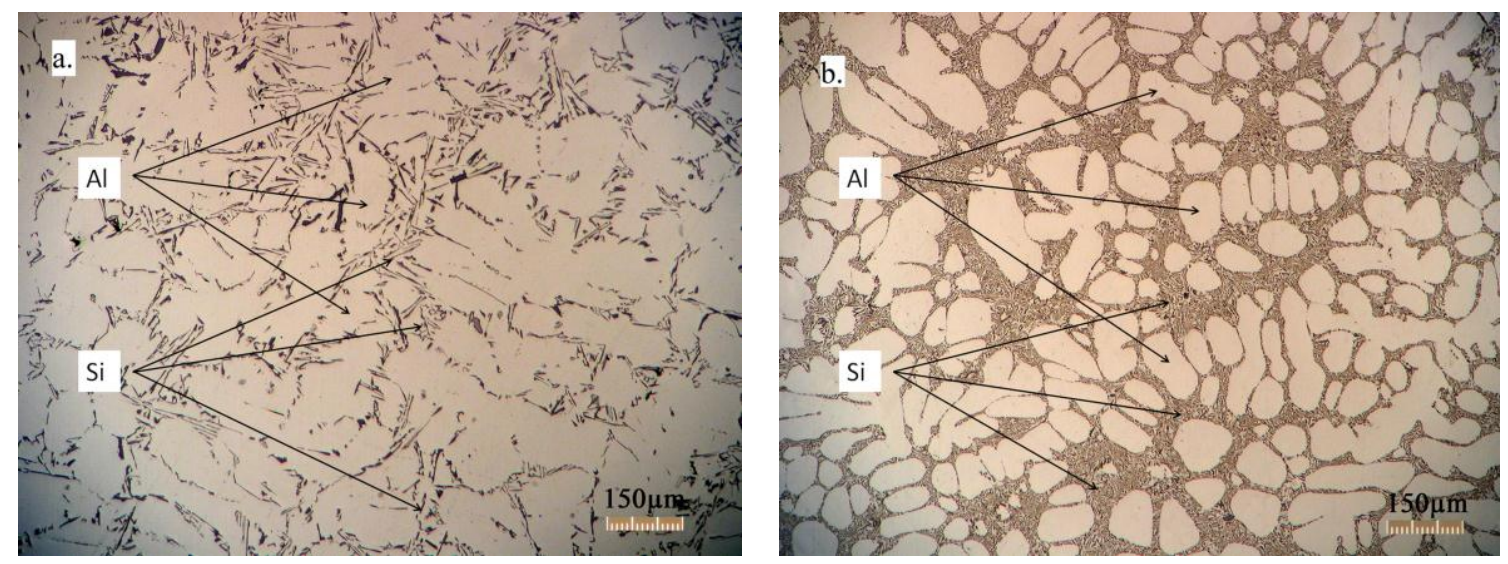

Figure 3. Optical micrographs of A356 alloy before (a) and after GDT (b). Large $\alpha$-Al grains are refined into fine equiaxed grains surrounded by homogeneously-distributed eutectic Si particles.

The average grain size changes were calculated according to ASTM E112-96 from the microstructures shown in Figure 3a,b using ImageJ 1.49v software by National Institute of Health, Bethesda, MD, USA. It was found that the average grain size reduced by 33\%, from $95 \mu \mathrm{m}$ down to $63.5 \mu \mathrm{m}$. 
This grain refinement induces changes in the mechanical properties of the metals, which will be discussed in greater detail below. The strengthening mechanism for an A356 alloy modified by ceramic nanoparticles was described in [21]. It was found that the nanoparticles act as nucleation accelerators in the crystallization process and that a grain boundary mechanism is responsible for the strengthening process. TiCN nanoparticles were used in the current research, as they have the same cubic crystal structure and Fm-3m space group as aluminum; therefore, they act as a nucleation accelerator belonging to the second type of modifiers mentioned above.

A combined technology with GDT and modification by TiCN nanoparticles was implemented in aluminum A356 casting alloy. Figure 4 shows cylindrical casts obtained after pouring into pre-heated cast iron molds. It is clearly seen that the shrinkage defect is reduced significantly after the combined treatment with GDT and additions of ceramic nanoparticles.

An XRD study was conducted to determine whether any phase changes occurred in the alloy after the modification process using additions of TiCN nanoparticles. XRD patterns of the modified and unmodified A356 casting alloy are shown in Figure 5.

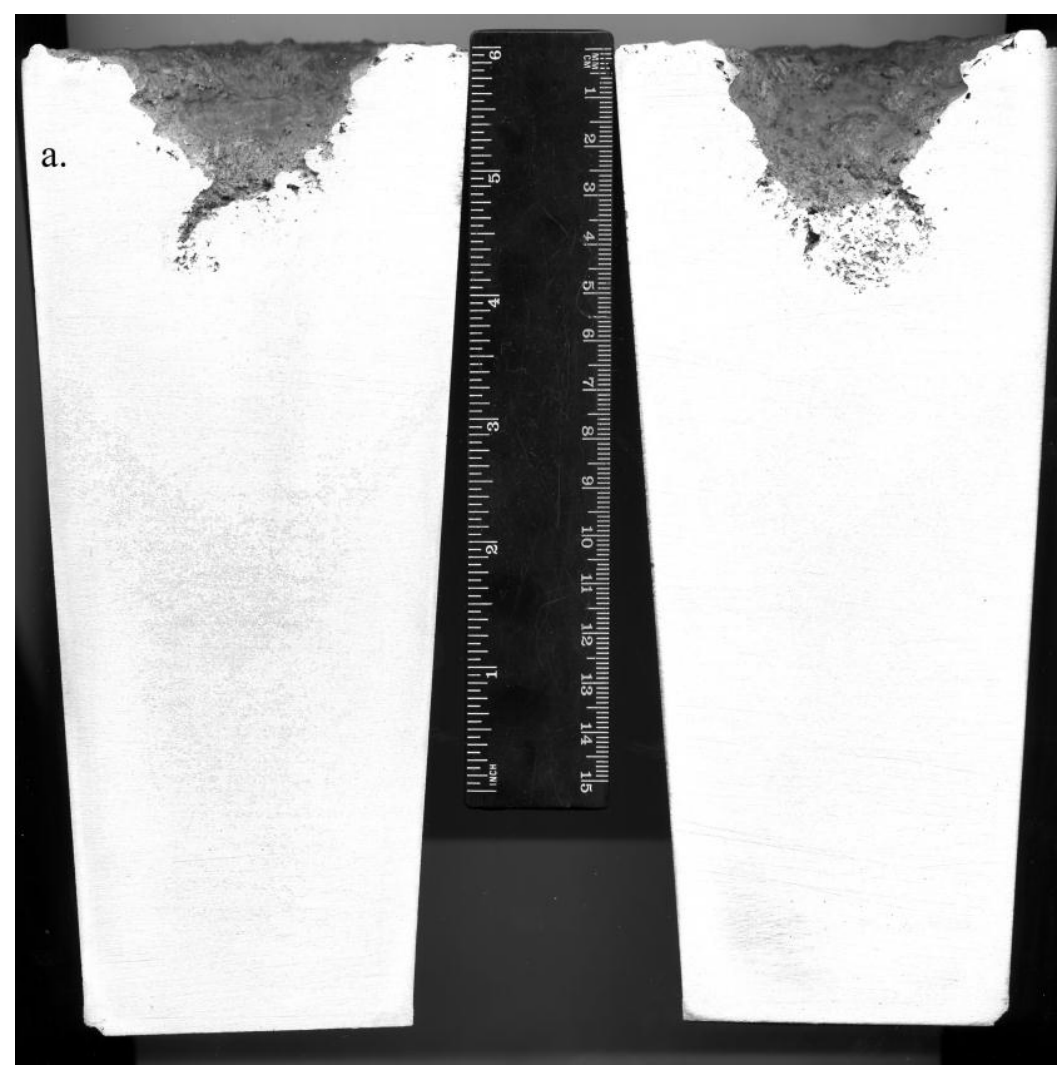

Figure 4. Cont. 


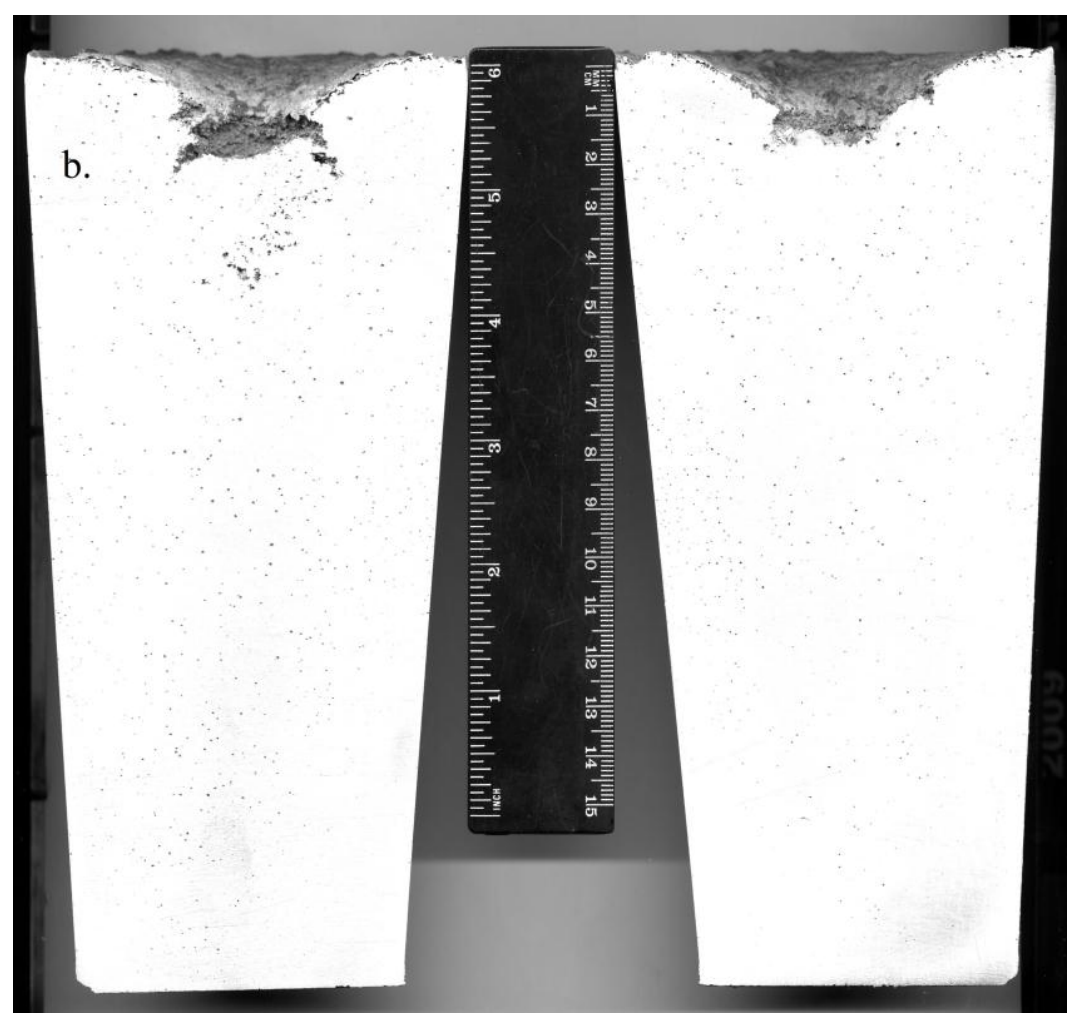

Figure 4. Cylindrical casts produced using the conventional technology (a) and the combined effect by GDT and modification by TiCN (b). The shrinkage defect in the untreated alloy is much greater than in the treated alloy.

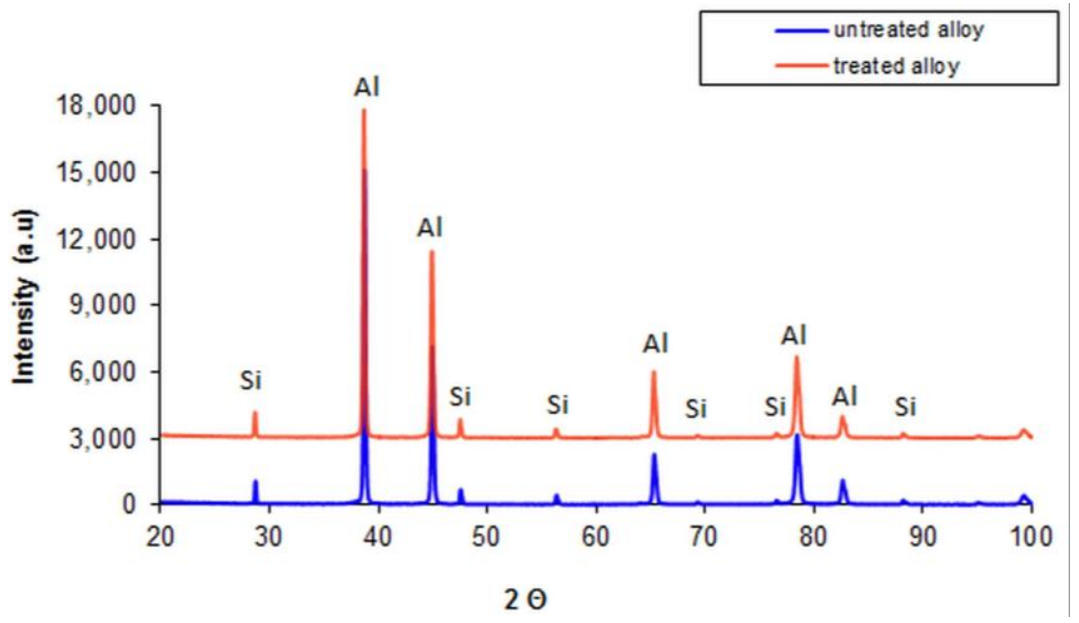

Figure 5. XRD patterns of A356 alloy before and after modification process by TiCN nanoparticles.

The XRD results indicate the presence of only aluminum (JCPDS 01-071-4624) and silicon (JCPDS 01-070-5680) phases. No difference caused by the modification was observed; therefore, no new phase formed in a detectable amount.

The evidence of the TiCN nanoparticles' presence was found in TEM images (Figure 6) and energy dispersive X-ray (EDS) analysis results (Table 2). Different points were analyzed, as shown in Figure 6. As seen in the image, TiCN nanoparticles (Points a and c) were distributed into Al grains (Point b) of the alloy. 


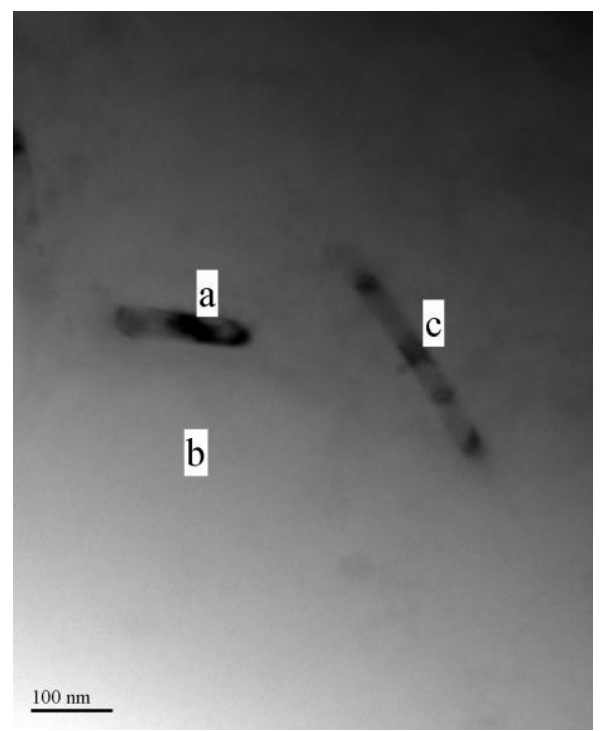

Figure 6. TEM image of A356 alloy after the modification process by TiCN nanoparticles.

Table 2. EDS analysis results of the treated A356 alloy.

\begin{tabular}{cccc}
\hline \multirow{2}{*}{ Element } & \multicolumn{3}{c}{ Weight \% } \\
\cline { 2 - 4 } & Point a & Point b & Point c \\
\hline $\mathrm{Al}$ & $91.69 \pm 0.50$ & $98.16 \pm 0.60$ & $92.81 \pm 0.52$ \\
$\mathrm{Si}$ & $3.96 \pm 0.17$ & $1.84 \pm 0.23$ & $3.65 \pm 0.22$ \\
$\mathrm{Ti}$ & $4.35 \pm 0.10$ & - & $3.54 \pm 0.09$ \\
\hline
\end{tabular}

Measurements of the mechanical properties were carried out on the untreated (as-cast) alloy and on samples subjected to gas dynamic treatment (GDT), modification by TiCN nanoparticles (M) and a combined treatment using GDT and modification $(\mathrm{GDT}+\mathrm{M})$. The results obtained are presented in Figures 7-9.

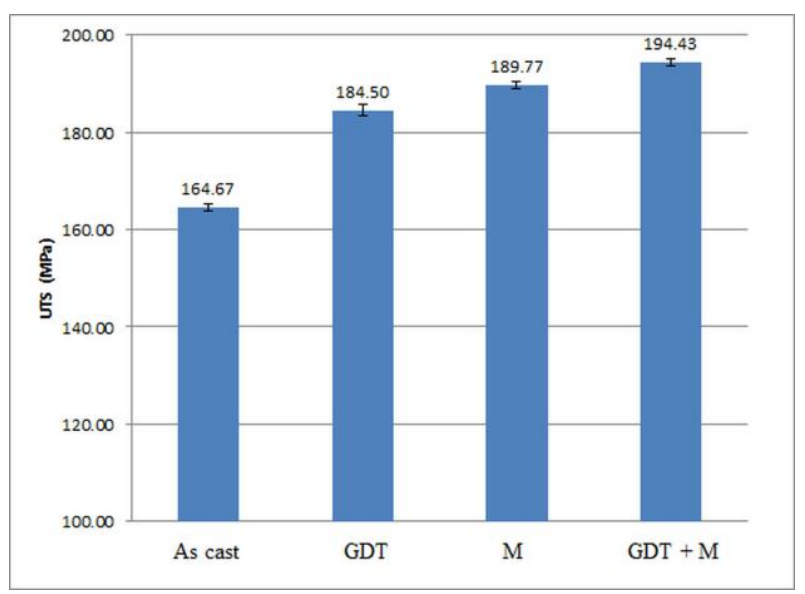

Figure 7. Results of ultimate tensile strength (UTS) measurements performed on A356 alloy. 


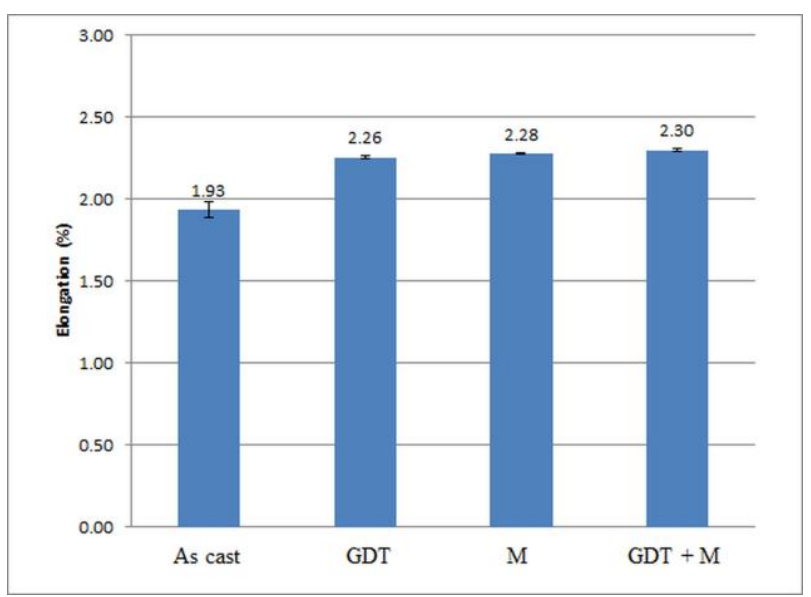

Figure 8. Results of elongation measurements performed on A356 alloy.

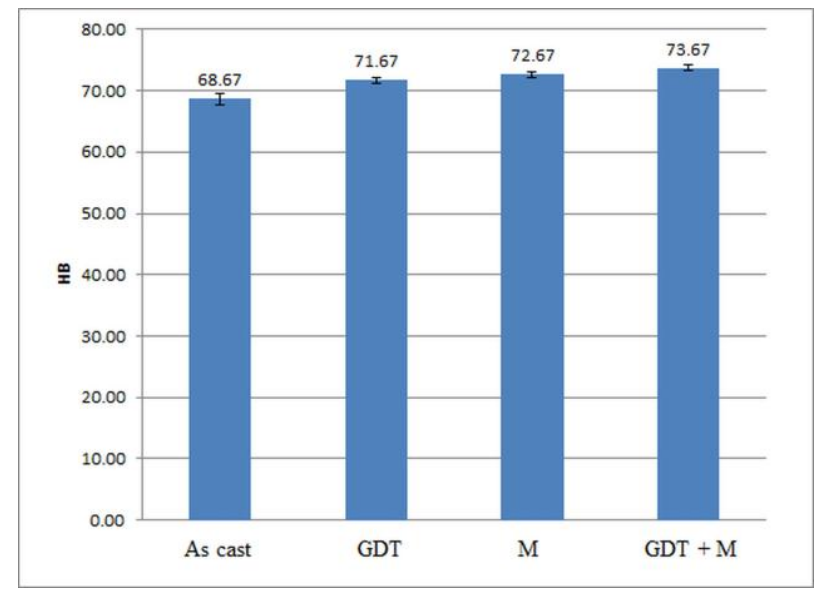

Figure 9. Results of hardness measurements performed on A356 alloy.

As is shown by the results of the mechanical properties measurements, the tensile strength of the GDT alloy improved by $12 \%$, that of the modified alloy by $15 \%$ and that of the alloy subjected to the combined treatment by $18 \%$. The elongation results showed the same behavior, with an improvement of $17 \%-19 \%$ of the treated alloys. The hardness results were slightly improved, as well; modification and treatment processes increased their value by $4.3 \%-7.3 \%$.

The strengthening of aluminum can usually be increased by several mechanisms:

(1) Solid-solution strengthening when the dislocation motion in the lattice is prevented by the formed solid solution.

(2) Grain-size strengthening expressed by the Hall-Petch equation relation [26]:

$$
\sigma_{y}=\sigma_{0}+K d^{-\frac{1}{2}}
$$

where $\sigma_{y}$ is the yield stress of the alloy, $\sigma_{0}$ is a material's constant for the starting stress for dislocation movement, $d$ is the average grain diameter and $K$ is the strengthening coefficient (which is specific to each material).

(3) Aging, which is the process of the fixation of the high-temperature structure of alloys at lower temperatures. 
Electron microscopy observation was performed to determine the mechanism of the strengthening that occurs in the alloy. Figure 10 shows an electron microscopy image of a grain boundary of the modified alloy. A high dislocation concentration was observed near the grain boundaries.

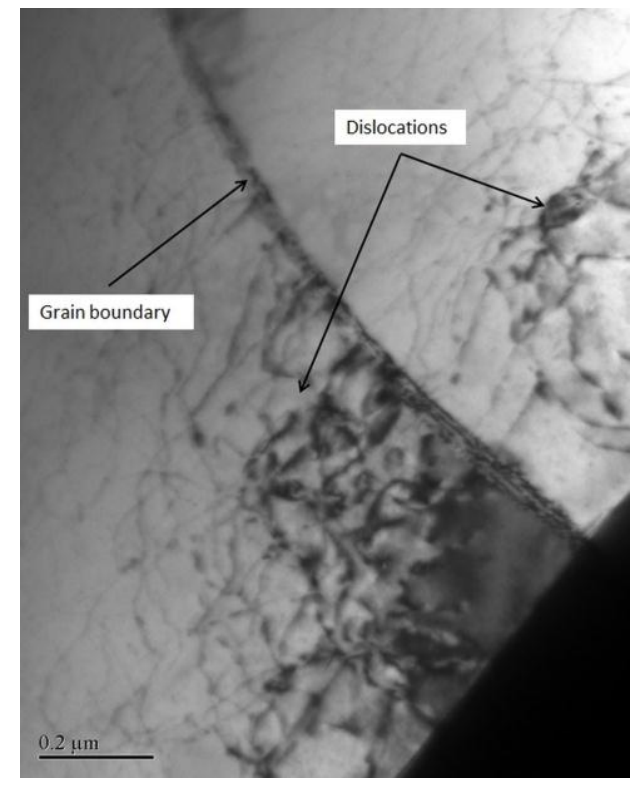

Figure 10. TEM image of A356 alloy after the modification process by TiCN nanoparticles with a high concentration of dislocations near a grain boundary of the alloy.

Based on the results obtained in the present study, together with our previous experimental results [21], it is suggested that a grain-size strengthening mechanism is at work in the process.

\section{Conclusions}

The effect of modification with TiCN nanoparticles, GDT and a combined treatment on aluminum casting alloy A356 has been investigated. Improvement of the mechanical properties was demonstrated after all three different treatments. GDT alone showed the smallest improvement, while the combined treatment showed the greatest. The tensile strength and elongation increased after the combined treatment by $18 \%$ and $19 \%$, respectively, and the hardness of the materials improved by $7.3 \%$.

The results of the experimental work demonstrate microstructural refinement of the A356 alloy. Phase analysis showed that no new phase was formed after the addition of ceramic nanoparticles, while TEM images showed that Ti-based nanoparticles were found in Al grains. Based on these results together with the mechanical properties' results, it can be safely assumed that a grain-size strengthening mechanism operates in the combined process.

\section{Author Contributions}

Konstantin Borodianskiy, Michael Zinigrad, Yuri Dotsenko and Vadim Selivorstov designed the experiments. Shrinkage defects and mechanical properties tests were performed by Yuri Dotsenko and Vadim Selivorstov. XRD results and electron microscopy were performed by Konstantin Borodianskiy. The manuscript was written and revised by Konstantin Borodianskiy with the help of Michael Zinigrad, Yuri Dotsenko and Vadim Selivorstov. 


\section{Conflicts of Interest}

The authors declare no conflict of interest.

\section{References}

1. Callister, W.D. Materials Science and Engineering, 7th ed.; John Wiley \& Sons Inc.: Hoboken, NJ, USA, 2007.

2. Birol, $\mathrm{Y} . \mathrm{AlB}_{3}$ master alloy to grain refine $\mathrm{AlSi}_{10} \mathrm{Mg}$ and $\mathrm{AlSi}_{12} \mathrm{Cu}$ aluminum foundry alloys. J. Alloys Compd. 2012, 513, 150-153.

3. Schaffer, P.L.; Dahle, A.K. Settling behavior of different grain refiners in aluminum. Mater. Sci. Eng. A 2005, 413-414, 373-378.

4. Mohanty, P.S.; Gruzleski, J.E. Mechanism of grain refinement in aluminum. Acta Metall. Mater. 1995, 43, 2001-2012.

5. Wang, C.; Wang, M.; Yu, B.; Chen, D.; Qin, P.; Feng, M.; Dai, Q. The grain refinement behavior of $\mathrm{TiB}_{2}$ particles prepared with in situ technology. Mater. Sci. Eng. A 2007, 459, 238-243.

6. Daoud, A.; Abo-Elkhar, M. Influence of $\mathrm{Al}_{2} \mathrm{O}_{3}$ or $\mathrm{ZrO}_{2}$ particulate addition on the microstructure aspects of AlNi and AlSi alloys. J. Mater. Process. Technol. 2002, 120, 296-302.

7. Chou, N.-S.; Huang, J.-L.; Lii, D.-F.; Lu, H.-H. The mechanical properties of $\mathrm{Al}_{2} \mathrm{O}_{3} /$ aluminum alloy A356 composite manufactured by squeeze casting. J. Alloys Compd. 2006, 419, 98-102.

8. Han, Y.; Le, K.; Wang, J.; Shu, D.; Sun, B. Influence of high-intensity ultrasound on grain refining performance of Al-5Ti-1B master alloy on aluminum. Mater. Sci. Eng. A 2005, 405, 306-312.

9. Das, A.; Kotadia, H.R. Effect of high-intensity ultrasonic irradiation on the modification of solidification microstructure in a Si-rich hypoeutectic Al-Si alloy. Mater. Chem. Phys. 2011, 125, 853-859.

10. Zhang, S.; Zhao, Y.; Cheng, X.; Chen, G.; Dai, Q. High-energy ultrasonic field effects on the microstructure and mechanical behaviors of A356 alloy. J. Alloys Compd. 2009, 470, 168-172.

11. Lu, H.T.; Wang, L.C.; Kung, S.K. Grain Refining in A356 Alloys. J. Chin. Foundrym. Assoc. 1981, 29, 10-18.

12. Sigworth, G.K.; Guzowski, M.M. Grain refining of Hypo-eutectic Al-Si alloys. ASF Trans. 1985, 93, 907-912.

13. Shi, Z.M.; Wang, Q.; Zhao, G.; Zhang, R.Y. Effects of erbium modification on the microstructure and mechanical properties of A356 aluminum alloys. Mater. Sci. Eng. A 2015, 626, 102-107.

14. Torre, A.D.L.; Pérez-Bustamante, R.; Camarillo-Cisneros, J.; Gómez-Esparza, C.D.; Medrano-Prieto, H.M.; Martínez-Sánchez, R. Mechanical properties of the A356 aluminum alloy modified with La/Ce. J. Rare Earths 2013, 31, 811-816.

15. Rebinder, P.A.; Lipman, M.S. Research in the Field of Applied Physico-Chemical Surface Behavior; USSR Academy of Sciences Publishers: Moscow, Russia, 1936.

16. Khodaverdizadeh, H.; Niroumand, B. Effects of applied pressure on microstructure and mechanical properties of squeeze cast ductile iron. Mater. Des. 2011, 32, 4747-4755.

17. Guan, R.G. Microstructure and properties of squeeze cast A356 alloy processed with a vibrating slope. J. Mater. Process. Technol. 2016, 229, 514-519. 
18. Selivorstov, V.; Dotsenko, Y.; Selivorstova, T.; Dotsenko, N. The use of gas-dynamic pressure to improve the mechanical properties of aluminum casting alloys with high iron content. Syst. Technol. 2015, 2, 68-74.

19. Sajjadi, S.A.; Parizi, M.T.; Ezatpour, H.R.; Sedghic, A. Fabrication of A356 composite reinforced with micro and nano $\mathrm{Al}_{2} \mathrm{O}_{3}$ particles by a developed compocasting method and study of its properties. J. Alloys Compd. 2012, 511, 226-231.

20. Akbari, M.K.; Baharvandi, H.R.; Shirvanimoghaddam, K. Tensile and fracture behavior of nano/micro $\mathrm{TiB}_{2}$ particle reinforced casting A356 aluminum alloy composites. Mater. Des. 2015, $66,150-161$.

21. Borodianskiy, K.; Kossenko, A.; Zinigrad, M. Improvement of the Mechanical Properties of Al-Si Alloys by TiC Nanoparticles. Metall. Mater. Trans. 2013, 44a, 4948-4953.

22. Schröder, E. About a solid body solubility dependence on its melting temperature. Z. Phyzik. Chem. 1893, 11, 449-465.

23. Markov, V.V.; Rizhikov, A.A. Heat Transfer between Cast and Mold; High School Publ.: Minsk, Russia, 1967; pp. 71-74.

24. Massalski, T.B. Binary Alloy Phase Diagrams; ASM International: Materials Park, OH, USA, 1990; Volume 1, pp. 211-213.

25. Shin, S.S.; Kim, E.S.; Yeom, G.Y.; Lee, J.C. Modification effect of Sr on the microstructures and mechanical properties of Al-10.5Si-2.0Cu recycled alloy for die casting. Mater. Sci. Eng. A 2012, $532,151-157$.

26. Hall, E.O. The deformation and aging of mild steel: III discussion and results. Proc. Phys. Soc. 1951, 643, 747-753.

(C) 2015 by the authors; licensee MDPI, Basel, Switzerland. This article is an open access article distributed under the terms and conditions of the Creative Commons Attribution license (http://creativecommons.org/licenses/by/4.0/). 